\title{
Pengelolaan Sampah Plastik Domestik Menjadi Wadah Media Tanam Sayuran
}

\author{
Wirdati Irma $^{1}$, Sri Hilma Siregar ${ }^{1}$, Neng Murialti ${ }^{2}$ \\ ${ }^{1}$ Fakultas MIPA dan Kesehatan, Universitas Muhammadiyah Riau \\ ${ }^{2}$ Fakultas konomi dan Bisnis, Universitas Muhammadiyah Riau \\ email:wirdati.irma@umri.ac.id
}

\begin{abstract}
Domestic plastic waste generated during the Covid-19 pandemic is currently increasing. The increase in plastic waste is due to new habits that must be implemented during Covid-19. New habits by staying at home, working at home, and almost all activities only done at home. The purpose of this service is to improve/skill/soft skills of less productive/non-productive communities (recycle plastic waste), increase the application of science and technology in processing plastic waste, and help meet family resilience in the food needs of villagers during the Covid 19 Pandemic. Methods The activities carried out are counseling, question and answer, soft skill training. The results of this service are as many as 30 mothers in RT 01 RW 02 Tarai Bangun Village, Tambang District, get skills/soft skills to recycle plastic waste, can apply science and technology in plastic waste management, and help meet their daily vegetable needs during the Covid pandemic-19.
\end{abstract}

Keywords: Covid-19 Pandemic, Domestik Plastic Waste, Family Resilience, New Habits, and Soft Skill

\begin{abstract}
Abstrak
Limbah plastic domestic yang dihasilkan dimasa pandemic Covid-19 saat ini semakin meningat. Meningkatnya limbah plastic karena kebiasaan baru yang harus diterapkan selama Covid-19. Kebiasaan baru dengan tetap tinggal di rumah, bekerja di rumah, dan hampir semua kegiatan hanya dilakukan di rumah. Tujuan dilaksanakannya pengabdian ini adalah untuk meningkatkan/ ketrampilan / soft skill masyarakat kurang produktif/non-produktif (recycle limbah plastik), meningkatkan penerapan IPTEK dalam pengolahan limbah plastic, dan membantu memenuhi kelentingan keluarga dalam kebutuhan pangan penduduk desa pada kondisi Pandemik Covid 19. Metode yang dilakukan adalah ceramah-penyuluhan, tanya jawab, pelatihan shoft skill. Hasil dari pengabdian ini adalah sebanyak 30 ibu-ibu di RT 01 RW 02 Desa Tarai Bangun Kecamatan Tambang mendapatkan keterampilan/soft skill untuk mendaur ulang limbah plastic, dapat menerapkan IPTEK dalam pengelolaan limbah plastic, dan membantu memenuhi kebutuhan sayur sehari-harinya dimasa pandemic Covid-19.
\end{abstract}

Kata Kunci: Limbah Plastik domestik, Kebiasaan baru, kelentingan keluarga, Pandemi Covid-19, shoft skill

\section{PENDAHULUAN}

Sampah plastic semakin hari semakin banyak produksinya. Menurut Jambeck (2015), Indonesia urutan ke 2 dunia setelah cina penghasil limbah plastic. Masa pandemic Covid-19 menyebabkan masyarakat mempunyai kebiasaan baru, sehingga mengakibatkan produksi sampah plastic menjadi lebih meningkat.
Kebiasaan baru yang terlahir dari situasi ini adalah lebih banyak berdiam diri di rumah, menghindari tempat keramaian, selalu memakai masker dan sering mencuci tangan. Hampir 70\%-90\% perkejaan dilakukan di rumah. Kondisi ini menyebabkan potensi timbunan sampah domestic, terutama sampah plastic semakin hari semakin meningkat. 
Jumlah penduduk yang bertambah juga menjadi pemicu penumpukan limbah, terutama limbah plastic Menurut Apriyani at all (2020) limbah berkaitan erat dengan pertumbuhan penduduk yang cenderung meningkat terutama pada pola hidup masyarakat, termasuk juga limbah plastic domestic. Berdasarkan data kependudukan dari kantor Desa Tarai Bangun pada bulan Januari 2014, jumlah penduduk Desa Tarai Bangun Kecamatan Tambang Kab. Kampar tercatat 19.057 jiwa. Mengalami kenaikan jumlah penduduk di tahun 2015 menjadi 29.987 Jiwa. Tahun 2016 mengalami penambahan kembali menjadi 30.676 Jiwa. (BPS, 2021).

Penamabahan jumlah penduduk ini mengakibatkan dampak penambahan jumlah limbah terutama limbah plastic. Apalagi di masa pandemic Covid 19 yang menerapkan aturan baru. Keberadaan masyarakat lebih banyak di rumah, mulai dari pagi hingga esok pagi lagi. Semua kegiatan yang dilakukan di rumah membuahkan limbah plastic dan tidak bisa lepas dari kehidupan sehari-hari (Nasution, S.R., 2015) . Hal ini merupakan salah satu upaya antisipasi untuk sterilisasi dan protocol kesehatan yang harus diterapkan. Plastic menjadi media yang sangat penting dan selalu menjadi pembungkus setiap barang atau apapun yang diperlukan dan yang dipesan masyarakat untuk keperluan selama di rumah. Faren dan Fardilla Putri (2021), yang melakukan penelitian di kota Padang menyatakan bahwa selama pandemic covid 19 ini limbah makanan dan plastic meningkat jumlahnya.

Limbah plastic yang dihasilkan mempunyai komposisi yang berbeda dan bervariasi. Tergantung dari peruntukkan plastic tersebut. Menurut Pamungkas F, (2014) beberapa jenis komposisi plastic adalah Polypropylene (PP), polyethylene therephthalate (PET/PETE), high density polyethylene (HDPE), polyvinyl chloride (PVC), dan low density polyethylene (LDPE). Komposisi plastic ini dapat dilihat pada Gambar diagram berikut:

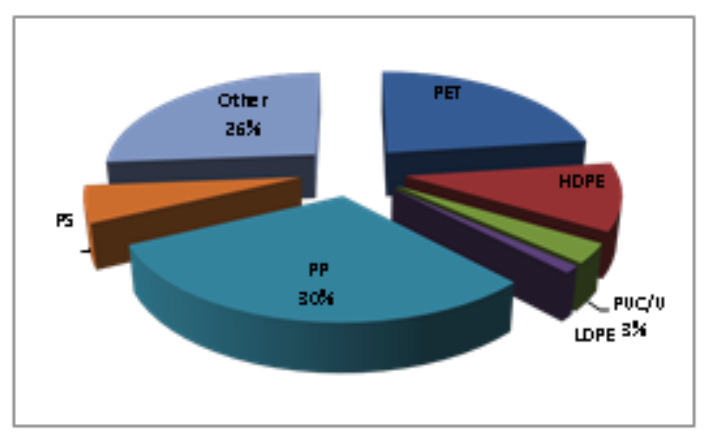

Gambar 1. Komposisi limbah plastic di alam

Pemerintah Republik Indonesia (RI) tergabung dalam Global Plastic Action Partnership, sebuah platform kolaborasi publik-swasta baru yang diluncurkan di World Economic Forum. Komitmen Indonesia dalam wadah tersebut adalah memerangi limbah plastik menjadi salah satu agenda prioritas nasional (Kemenko Marves, 2020). Meskipun masyarakat belum bisa meninggalkan plastic, namun upaya untuk mengelola limbah plastic dapat dilakukan mulai dari dalam keluarga. Plastic-plastik yang dihasilkan di domestic dapat dimanfaatkan kembali dengan cara yang ramah lingkungan, seperti untuk wadah menanam sayur. Keberadaan limbah plastic yang tidak bisa dihentikan ini diupayakan tidak membahayakan dan mencemari lingkungan.

Tujuan dilakukannya kegiatan adalah Meningkatkan ketrampilan masyarakat kurang produktif, penerapan iptek limbah plastic domestic menjadi wadah tanam sayur, dan meningkatkan kelentingan keluarga dalam memenuhi kebutuhan pangan keluarga.

\section{METODE PENGABDIAN}

Metode yang digunakan adalah penyuluhan-ceramah, tanya jawab, pelatihan shoft skill terhadap 30 orang ibuibu di RT 01 dan RW 02 Desa Tarai Bangun Kec. Tambang. Rancangan kegiatan yang dilakukan adalah Sosialisasi Program, Pelaksanaan kegiatan diawali 
dengan sosialisasi program kepada masyarakat/penduduk desa mengenai lingkup program yang akan dilaksanakan, waktu pelaksanaan kegiatan, tahapan kegiatan, pelatihan soft skill.

Sosialisasi awal kepada Bapak Kepala Desa Tarai Bangun sebagai aparat desa untuk menentukan lokasi penyuluhan, edukasi dan pelatihan dilakukan. Beberapa RT dan RW yang ada di Desa Tarai Bangun ini rata-rata merupakan masyarakat pendatang dengan pekerjaan yang bervariasi. Sosialisasi dilakukan langsung dengan mendatangi lokasi yang sudah ditentukan untuk ditetapkan waktu pelaksanaan penyuluhan, edukasi dan pelatiahan.

Edukasi mengenai pemanfaatan sampah plastik sebagai wadah tanam sayuran di masa pandemik Covid 19 bagi masyarakat kurang produktif yang tidak mempunyai lahan atau lahan terbatas agar dapat mempertahankan kelentingan keluarga. Terutama pada pemenuhan pangan, dalam hal ini adalah sayur-mayur. Pelatihan Soft Skill pembuatan wadah tanam sayur dari sampah plastik domestik berupa tas kresek atau kantong plastik, bekas deterjen, bekas minyak goreng, bekas botol miniman dan sampah plastik lainnya yang dapat digunakan sebagai wadah tanam sayur.

Analisis dilakukan secara diskriptif dari hasil sosialisasi dengan penyuluhan, edukasi dan pelatihan. Selanjutnya dilakukan monitoring langsung ke lapangan. Mengetahui secara langsung apakah kegiatan ini dapat berjalan dan dapat dilakukan dengan baik oleh masyarakat yang mendapatkan penyuluhan, edukasi dan pelatihan sebelumnya.

\section{HASIL DAN PEMBAHASAN}

1. Meningkatkan keterampilan masyarakat kurang produktif
Pelaksanaan penyuluhan yang dilakukan terhadap ibu-ibu RT 01 RW 02 Desa Tarai Bangun Kecamatan Tambang ini diikuti sebanyak 30 orang. Diharahpkan dengan $30 \mathrm{ibu}$ dari masingmasing kepala rumah tangga dapat sadar tentang bahayanya limbah plastic jika tidak dikelola dengan baik dan benar. Penyuluhan dengan metode ceramah ini diikuti ibu-ibu dengan antusias mengingat selama ini, ibu-ibu tidak bisa maksimal mengelola limbah plastic yang biasa dihasilkan setiap harinya. Di masa pandemic Covid-19 yang sudah lebih dari satu tahun ini membuat masyarakat lebih konsumtif sehingga lebih banyak menghasilkan limbah plastic. Limbah plastic yang biasa dihasilkan dalam rumah tangga ibu-ibu di RT 01 dan RW 02 ini dapat di lihat pada Tabel 1.

Tabel 1. Jenis-jenis limbah plastic

\begin{tabular}{|l|l|}
\hline No & Jenis Limbah Plastik \\
\hline 1 & Wadah Deterjen dan pewangi \\
\hline 2 & Wadah Minyak Goreng \\
\hline 3 & Kantong Plastik (Kresek) \\
\hline 4 & Wadah makanan \\
\hline 5 & Wadah minuman \\
\hline 6 & Karung plastic \\
\hline
\end{tabular}

Ke-enam jenis limbah plastic ini pada umumnya dihasilkan oleh domestic. Menurut Pramiati P. (2016), sampah plastic yang terbanyak adalah jenis kantong plastic atau kantong kresek selain Plastic kemasan. Ibu-ibu RT 01 RW 02 mengaku bahwa limbah plastic yang mereka hasilkan hampir setiap hari hanya dibuang saja ke lingkungan. Tentu hal ini akan sangat berbahaya bagi lingkungan. Limbah plastic yang langsung dibuang ke lingkungan akan mencemari lingkungan terutama pada tanah. Menurut R. Andi., dkk (2020) bahaya limbah plastic bagi lingkungan, sampah dari plastik sangat sulit diolah dan terurai oleh tanah. Akhirnya dapat merusak tanah, mencemari tanah dan sumber air tanah. 
Limbah plastic tidak dapat didegradasi oleh bakteri yang ada di tanah, sehingga menyebabkan limbah plastic tidak hancur dan tidak dapat menyatu dengan tanah. Pramiati P (2016), sampah plastik yang berada dalam tanah yang tidak dapat diuraikan oleh mikroorganisme menyebabkan mineral-mineral dalam tanah baik organik maupun anorganik semakin berkurang, hal ini menyebabkan jarangnya fauna tanah, seperti cacing dan mikorganisme tanah, yang hidup pada area tanah tersebut, dikarenakan sulitnya untuk memperoleh makanan dan berlindung. Selain itu kadar O2 dalam tanah semakin sedikit, sehingga fauna tanah sulit untuk bernafas dan akhirnya mati.

Akibatnya tanah tidak dapat berfungsi seperti peruntukannya untuk mendukung kehidupan tumbuhan dengan baik. Tanah tidak subur dan tidak dapat menjadi media tanam bagi tumbuhan. Tanah yang demikian akan sulit untuk dipulihkan kembali, karena sudah masuk ke dalam kategori tercemar limbah plastic.

Penyuluhan yang dilakukan secara ceramah ini membuka wawasan ibu-ibu tentang bahaya limbah plastic. Selanjutnya tim pengabdian dari dosen Universitas Muhammadiyah Riau berkolaborasi dengan tim Lembaga Lingkungan Hidup dan Penanggulangan Bencana Pimpinan Wilayah Riau (LLHPB PWA Riau) memberikan edukasi tentang pemanfaatan limbah plastic.

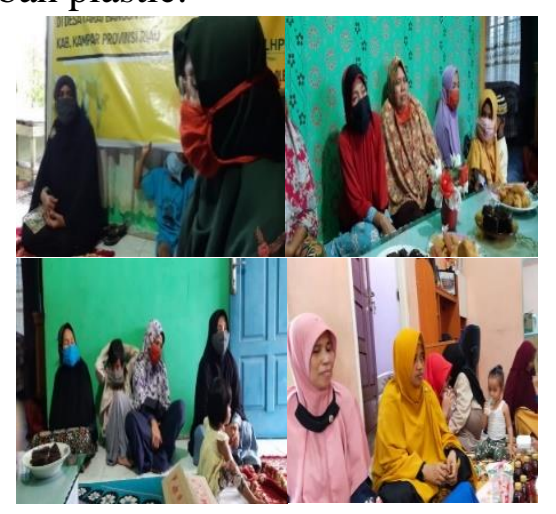

Gambar 2. Pengabdian Masyarakat (Penyuluhanceramah Ibu-ibu RT 01 RW 02 Desa TArai BangunModel Rekayasa Limbah Plastik)

Sejauh ini ibu-ibu hanya tahu bahwa kantong plastic (kresek) yang biasa digunakan untuk membungkus habis belanja tidak bisa digunakan kembali. Jikapun bisa digunakan hanya sekeder untuk wadah pembungkus kembali. Edukasi yang diberikan mengenai pemanfaatan limbah plastic itu dapat digunakan sebagai wadah tanah untuk menanam sayuran. Limbah plastic yang dihasilkan dari domestic hariharinya tidak lagi dibuang ke lingkungan begitu saja, namun dapat dimanfaatkan untuk menanam sayur, sehingga tidak perlu mengeluarkan biaya untuk membeli wadah tanaman. Tentu hal ini dapat menghemat pengeluaran dimasa pandemic Covid-19 saat ini.

2. Penerapan IPTEK dari Limbah Plastik

Limbah plastic yang digunakan sebagai wadah tanah untuk menanam sayuran ini dapat langsung digunakan dengan memberikan sedikit lubang di bawah wadah tersebut. Fungsi lubang yang dibuat adalah untuk pori-pori bagi tanah dan air dapat bersikulasi dengan baik. Air, udara dan organisme yang ada di dalam wadah plastic dapat keluar dan masuk melalui poripori yang dibuat.

Limbah plastic yang sudah dilubangi dapat langsung diisi dengan tanah untuk media tumbuh sayur. Limbah plastic berupa plastic kresek mendapat perlakuan khusus yakni dengan membuat plastic kresek menjadi 3 lapis minimal. Hal ini dilakukan mengingat plastic kresek sangat lunak dan gampang sobek, sehingga perlu dilapisi agar sedikit lebih kuat. Pengisian media tanah pada wadah limbah plastic tidak sampai penuh, namun di sisakan $1 / 3$ bagian dari limbah plastic. Bagian yang tidak diisi limbah plastic ini dimaksudnya untuk dilipat bagian atasnya 1-2 x lipatan. Lipatan kurang lebih sebesar 1-1.5 cm. pembuatan wadah media tanam sayur ini dapat dilihat pada Gambar 3. 


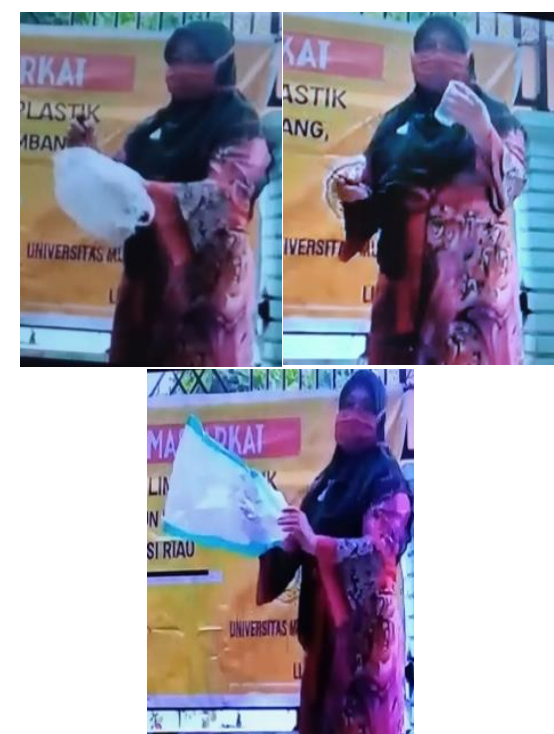

Gambar 3. Foto Edukasi Limbah Plastik

IPTEK model rekayasa limbah plastic domestik yang dilakukan agar, limbah plastic yang digunakan sebagai wadah media tanam sayuran dapat digunakan tahan lama dan menarik dipandang. Keberadaan limbah plastic ini juda dapat menjadi keindahan tersendiri bagi rumah. Mengingat kegiatan penanaman ini dilakukan di perakarangan rumah yang selalu dipandang banyak mata

\section{Kepentingan Keluarga}

Ibu-ibu RT 01 RW 02 yang mendapatkan penyuluhan-ceramah, pelatihan dan soft skill tentang penggunaan limbah plastic sebagai wadah media tanam sayur di berikan bibit sayuran lengkap dengan tanah dan pupuk untuk dapat menanam sayur secara mandiri di rumahnya masingmasing. Kelentingan keluarga dalam hal ini adalah pemenuhan kebutuhan sayur mayur di dalam keluarga bagi ibu-ibu yang kurang produktif. Menurunnya penghasilan akibat pandemic Covid-19 ini mengakibatkan menurunnya pemenuhan kebutuhan pangan bagi masyarakat terutama sayuran. Sayuran bagi sebagian masyarakat disaat pandemic ini hanya menambah pengeluaran yang tidak perlu.
Penanaman sendiri dengan teknik penggunaan limbah plastic sebagai wadah media tanam sayur sedikit mengurangi pengeluaran namun tetap dapat memenuhi kebutuhan akan pangan terutama sayuran. Oleh karenanya kelentingan keluarga akan

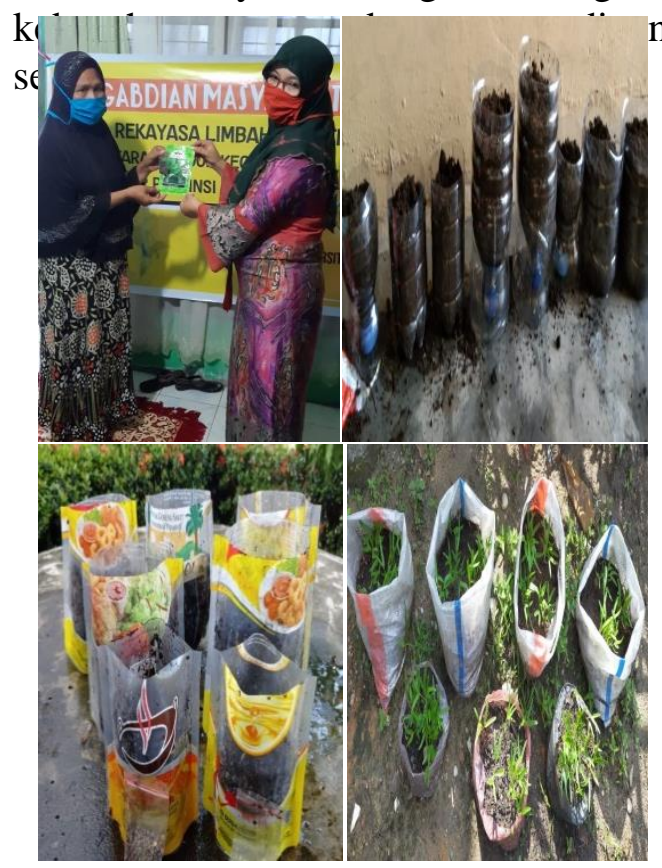

Gambar 4. Limbah Plastik Wadah Median Tanam Sayur

Bercocok tanam sayuran sendiri di rumah tidak membutuhkan biaya karena peralatan dan bahan yang digunakan selain didapat secara Cuma-Cuma, juga dapat disediakan sendiri dari limbah plastic yang dianggap tidak berguna lagi. Sesulit apapun kondisi saat pandemic Covid-19 ini menghinggapi kehidupan, namun masyarakat tidak boleh mengabaikan kebutuhan hidupnya. Kelentingan keluarga tetap harus dipertahankan, karena kader bangsa bermula dari keluarga yang terpenuhi kebutuhan pangannya. Jika kelengkapan pangan keluarga seperti sayur tidak terpenuhi, maka kelentingan keluarga juga tidak akan tercapai.

\section{SIMPULAN}

Kesimpulan yang diperoleh dari kegiatan pengabdian masyarakat tentang 
model rekayasa limbah plastic bagi ibu-ibu di RT 01 RW 02 Desa Tarai Bangun

Kecamatan Tambang adalah :

1. Peningkatan pengetahuan $30 \mathrm{ibu}-\mathrm{ibu}$ yang mendapatkan penyuluhan dan pengetahuan tentang pengelolaan limbah plastic domestic.

2. IPTEK yang diterapkan dari limbah plastic domestik adalah wadah media tanam sayur.

3. Kelentingan keluarga dalam pemenuhan kebutuhan pangan terutama sayuran dapat dipenuhi di masa pandemic Covid-19 dengan bercocok tanam sendiri di rumah.

\section{UCAPAN TERIMAKASIH}

Terima kasih yang terhingga kami ucapkan kepada :

1. Lembaga Penelitan dan Pengabdian Masyarakat Universitas Muhammadiyah (LP2M UMRI), yang telah memberikan dana sebesar Rp. 2.500.000,- untuk terselenggaranya pengabdian ini.

2. Kepala Desa Tarai Bangun Kecamatan Tambang yang sudah memberikan izin penulis untuk melakukan pengabdian di Desanya.

3. Ibu-ibu di RT 01 RW 02 yang telah bersedia mengikuti program pengabdian.

4. Kepada Ibu Dra. Mudarni Hidayati sebagai Penghubung ibu-ibu di RT 01 RW 02 untuk mengatur waktu dan melaksanakan pengabdian ini.

5. Para mahasiswa yang turut membantu terlaksananya pengabdian ini dengan baik.

6. Pihak-pihak terkaitan yang tidak dapat disebutkan satu-per-satu yang telah turut membantu dalam terlaksananya pengabdian ini.

\section{DAFTAR PUSTAKA}

[1]. Apriyani Apriyani, Mahadewi Mustika Putri, Samuel Yudha Wibowo. (2020). Pemanfaatan
Sampah Plastik Menjadi Ecobrick. Volume. 1. No.1 Hal. 48-50

[2]. Badan Pusat Statistik. (2021). Kampar dalam Angka. Kabupaten Kampar.

[3]. Faren, Putri F. 2021. Analisis Timbulan Dan Komposisi Sampah Rumah Tangga Selama Masa Pandemi Covid-19 Di Kota Padang. Skripsi. Universitas Andalas Padang.

[4]. Jenna R. Jambeck, Roland Geyer, Chris Wilcox, Theodore R. Siegler, Miriam Perryman, Anthony Andrady, Ramani Narayan, Kara Lavender Law. 2015. Plastic waste inputs from land into the ocean. Journal Science. Vol. 347. No. 6223. Hal. 768-771

[5]. Kemenko Marves. 2020. Pertumbuhan Bank Sampah di Indonesia. Majalah Marves Kemaritiman dan Investasi. Vol. 8 No.2 Hal. 20.

[6]. Nasution Silvia Reni. 2015. Berbagai Cara Penanggulangan Limbah Plastil. Journal of Islamic Science and Technology Vol. 1, No.1. Hal 97-104

[7]. R. Andi Ahmad Gunadi., Doby Putro Parlindungan., Apri Utami Parta Santi., Aswir Aswir., Adi Aburahman. 2020. Bahaya Plastik Bagi Kesehatan dan Lingkungan. Prossiding Seminar Nasional Pengabdian Masyarakat LPPM UMJ. Website: http://jurnal.umj.ac.id/index.php/sem naskat E ISSN: 2714-6286. Hal 1-6.

[8]. Pamungkas, Febrina PA, 2014, Analisis Karakter Sampah Plastik di Kecamatan Tebet dan Alternatif Pengolahannya, Laporan Tugas Akhir, Jurusan Teknik Lingkungan, FALTL Universitas Trisakti.

[9]. Prawita Purwaningrum. 2016. Upaya Mengurangi Timbunan Limbah Plastik di Lingkungan. Indonesian Journal of Urban and Environmental Technology. Vol. Vol 8. No. 2. Hal. 141-147 